\title{
Cristianismo y judaísmo en la vida de Abdías, el prosélito normando, a través de la profecía de Joel ${ }^{1}$
}

\author{
Sylvie Denise García de la Calle \\ Universidad de Granada \\ sgarciadelacalle@gmail.com
}

\begin{abstract}
RESUMEN
En la Genizah del Cairo se encontraron unos manuscritos con notación gregoriana y escritura hebrea. También aparecieron documentos que apuntan como autor de las partituras a Giovanni-Abdías, un monje cristiano del siglo XII, nacido en el sur de Italia, que se convirtió al judaísmo. Hasta ahora, el estudio de este personaje se ha realizado casi exclusivamente desde el punto de vista judío. Sin embargo, al igual que Abdías sintetiza las tradiciones cristiana y judía en su notación al copiar melodías hebreas con notación cristiana, también lo hace en sus textos. Abdías transcribió una cita latina de Joel a caracteres hebreos. Este artículo estudia la posibilidad de que Abdías pretendiera contraponer su conversión al judaísmo a su ordenación como monje cristiano a través de la plasmación de la profecía de Joel, lo que implica un intenso diálogo entre ambas tradiciones.
\end{abstract}

Palabras clave: Música judía, Genizah del Cairo, Mesianismo, Fiestas judías, Pentecostés, Prosélito normando.

Christianity and Judaism in the life of Obadiah, the Norman proselyte, through the prophecy of Joel

\begin{abstract}
In the Cairo Genizah were manuscripts with Gregorian notation and Hebrew script. They also appeared documents that point to author of the scores at Giovanni-Obadiah, a twelfth century Christian monk, born in southern Italy, who converted to Judaism. Until now, the study of this personage has been realized almost exclusively from the Jewish point of view. Nevertheless, like Obadiah synthesizes the traditions Christian and Jewish in its notation when copying Hebrew melodies with Christian notation, also it does in his texts. Obadiah transcribed a Latin appointment of Joel to Hebrew characters. This article pretends to oppose his conversion to Judaism with his ordination as a Christian monk through the prophecy of Joel, which implies an intense dialogue between the two traditions.
\end{abstract}

Keywords: Jewish Music, Cairo Genizah, Messianism, Jewish holidays, Pentecost, Norman proselyte.

${ }^{1}$ Este trabajo es fruto de la investigación que llevé a cabo para la realización de mi trabajo de fin de Máster. S. D. García de la Calle, Giovanni-Abdías, el prosélito normando: un músico entre dos tradiciones, Granada, Universidad de Granada, 2010 (sin publicar). 
SUMARIO: 1. Introducción. 2. Abdías, el prosélito normando. 3. La profecía de Joel. 4. Abdías y la visión escatológica de la profecía de Joel: la cuestión mesiánica. 5. El judaísmo en Giovanni-Abdías y la Fiesta de Pentecostés. 6. Conclusión.

FECHA DE RECEPCIÓN: 01 DE 02 DE 2011 FECHA DE ACEPTACIÓN: 05 DE 11 DE 2011

\section{INTRODUCCIÓN}

Resulta complicado estudiar la música judía, pues ha estado supeditada a la tradición oral durante siglos. Existen muchos escritos sobre música judía, pero es difícil encontrar documentos con contenido musical anteriores al siglo XVIII. Debido a esta ausencia, hay que recurrir a enfoques complementarios. Pese a ello, existe un hallazgo excepcional. En la Genizah del Cairo aparecieron unos manuscritos con notación gregoriana y escritura hebrea: un manuscrito de la colección E. N. Adler y un manuscrito que forma parte de la colección Taylor Schechter de la Biblioteca de la Universidad de Cambridge ${ }^{2}$.

Además de ello, en la Genizah del Cairo se encontraron documentos ${ }^{3}$ que apuntan como autor de estas partituras a Giovanni, un monje cristiano del siglo XII, de origen normando, nacido en Opido. Se convirtió al judaísmo, cambió su nombre por el de Abdías ${ }^{4}$ e inició un largo viaje que acabó en Egipto, donde escribió esos sorprendentes manuscritos con notación musical.

El ms. ENA contiene el piyyut Mi'al har oreb ${ }^{5}$, destinado a la fiesta de Simhat Torah. El ms. Cambridge contiene los fragmentos conocidos como Baruk ha-gever ${ }^{6}$ y Wa-eda'mah'.

Se ha discutido mucho en torno a cual es el rito que manifiesta Abdías en estos manuscritos. Somekh explica que el repertorio de Abdías refleja el rito sinagogal italiano ${ }^{8}$. Expone que el piyyut Mi al har oreb presenta un gran parecido con un piyyut destinado al rito italiano para la misma celebración litúrgica. Ambos piyyutim describen la teofanía con breves versículos seguidos por un estribillo. Según Werner, los cristianos empleaban este piyyut para el rito católico hasta el siglo XIII ${ }^{9}$. Afirma So-

2 También conocidos como ms. ENA y ms. Cambridge.

3 Siete hojas autobiográficas en hebreo, escritas en algún momento anterior a 1221, una carta de recomendación de un rabino de Alepo que proporciona más información biográfica, y una página del libro de rezos escrito por Abdías donde aparece la fecha de su conversión (año 1102).

${ }^{4}$ «Abdías» es un nombre común de prosélitos desde época pos talmúdica. El profeta Abdías era según el Talmud un idumeo que se convirtió al judaísmo. Existe también una tradición rabínica que identifica el pueblo judío y la civilización romano-cristiana respectivamente con los herederos Jacob y Esaú.

${ }^{5}$ Quien bajó del monte Oreb.

${ }^{6}$ Bendito el hombre.

${ }^{7}$ Que yo pueda saber.

${ }^{8}$ Véase A. M. Somekh, «Ovadiah il prosélito fra poesia e liturgia», en A. De Rosa y M. Perani (coords.), Giovanni-Ovadiah da Oppido, prosélito, viaggiatore e musicista dell'età normanna, (Actas del simposio internacional Oppido Lucano 28-30 marzo 2004), pp. 175-194.

${ }^{9}$ E. Werner, «The oldest sources of synagogal chant», en PAAJR 16 (1946-47), pp. 226s. 


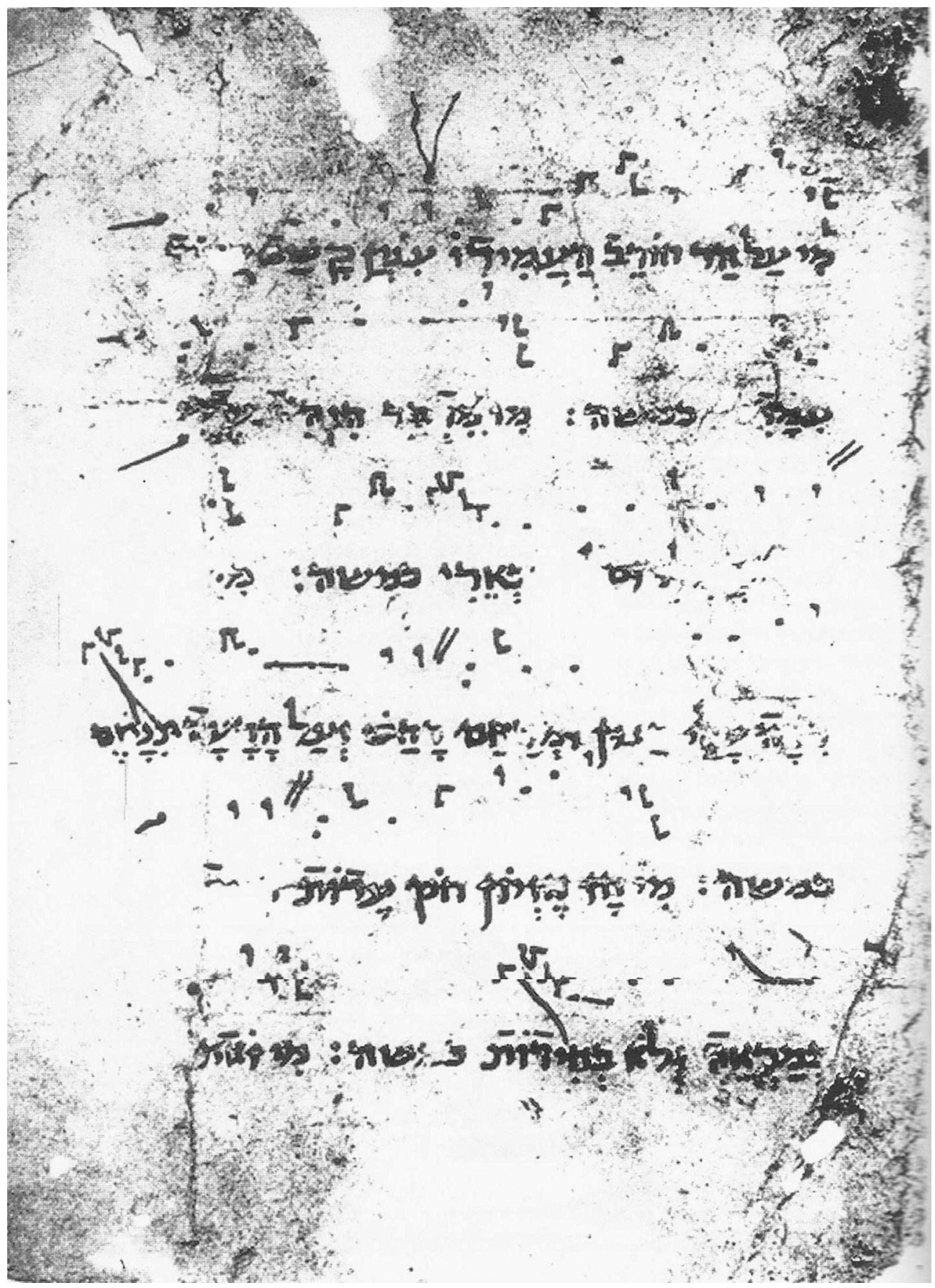

Mi'al har horev, un Elogio a Moisés, de Abdías, el prosélito normando, s. XII (después de 1102); ms. Nueva York, JTS, Colección Adler, ms. 4096b recto. 


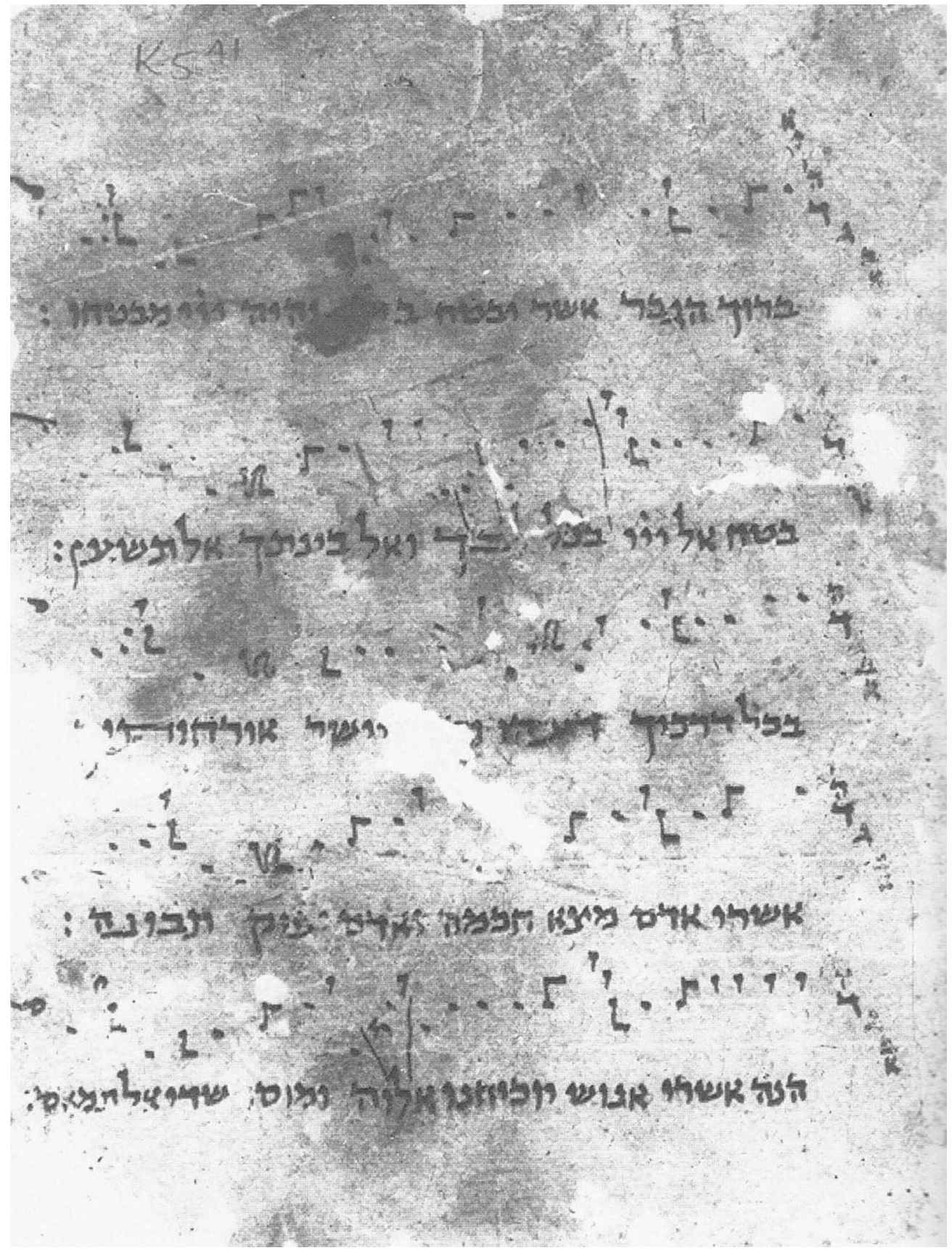

Cambridge University Library, collection Taylor-Schechter, K 5.41 recto. 
mekh además que el ms. Cambridge presenta cinco versos bíblicos completos y otros tres versos que probablemente formen parte de un piyyut. Los primeros versos hablan de la confianza en Dios. Los siguientes hacen alusión a los anteriores e introducen el piyyut. Esta intercalación que aparece en el ms. Cambridge se emplea en el rito italiano para celebrar Rosh Hashaná y Kippur.

Scheiber ${ }^{10}$ y Allony ${ }^{11}$ afirmaron que el repertorio de Abdías responde al rito palestino. Mann ${ }^{12}$ refuta esta propuesta alegando que no se puede discernir con tanta claridad al respecto el Talmud Palestinense del Talmud Babilónico ${ }^{13}$.

Flender apunta la posibilidad de que Abdías transcribiera cantilación judía procedente de Djerba ${ }^{14}$. La comunidad de Djerba ha sido un centro de interés para el estudio de la música judía desde hace más de medio siglo ${ }^{15}$. Robert Lachmann visitó Djerba en 1929 con la esperanza de encontrar trazos de canciones cantadas en el Templo de Jerusalén ${ }^{16}$. En 1979 Flender grabó una cantilación del salmo 1, cantado por Baruk Huri, un descendiente de Djerba. Aunque Baruk Huri ha vivido en Israel durante más de veinte años, esta versión es casi idéntica a la melodía transcrita por Lachmann más de cincuenta años atrás. Flender explica que la cláusula oleh we-yored cantada por Baruk Huri presenta similitudes con el modo empleado por Abdías en Baruk ha-gever. El modo de recitación de los judíos de Djerba es muy particular, no se emplea por ejemplo entre los judíos de Marruecos, Yemen ni los kurdos. Flender afirma con todo que la similitud entre la notación de Abdías y el modo de recitación de los judíos de Djerba es pues un fenómeno excepcional y que constituye un valioso testimonio de la fiabilidad de la tradición ora ${ }^{17}$.

Sin embargo, no hemos de olvidar el pasado cristiano de Abdías y su formación musical cuando era monje. La notación es occidental, de «tipo Benevento» ${ }^{18}$. En esta época y contexto Abdías no tiene otra manera de plasmar la música por escrito, ya que en la tradición judía no se escriben las melodías. Sin embargo, las evocaciones cristianas son evidentes, pues Abdías cumple las normas específicas del canto gregoriano ${ }^{19}$.

En definitiva, Abdías era un monje cristiano que decidió convertirse al judaísmo. Escribió esas partituras en Egipto, tras su conversión y en un entorno judío. Por eso lo más probable es que pretendiera que esa música formara parte del rito judío. Así, no sería de extrañar que la letra presentara reminiscencias del rito sinagogal italiano,

${ }^{10}$ A. Scheiber, «Mi-siddurehem šel gere ședeq», en Tarbiz 34 (1964-65), p. 366.

${ }^{11}$ N. Allony, «Me-ha-Mahzor le-Ovadyah ha-ger mi-Normandia», en Sinay 57 (1965), p. 52.

12 J. Mann, «Genizah Fragments of the Palestinian Order of service», en H.U.C.A. 2 (1925), p. 312.

13 Véase A. M. Somekh, op.cit. pp. 175-194.

${ }^{14}$ R. D. Flender, «Parallels between the notation of Ovadiah ha-Ger and a psalmodic cantillation transmitted in the oral tradition of the Jews of Djerba», en A. De Rosa y M. Perani (coords.), op. cit. pp. 225-229.

${ }^{15}$ H. Roten, Músicas litúrgicas judias, Madrid, 2002, pp. 99s.

${ }^{16}$ La comunidad de Djerba transmitió la leyenda de que vivió en un estricto aislamiento durante siglos, pero al analizar el material musical, Lachmann advirtió que el patrimonio estaba también influenciado por patrones musicales árabes.

${ }^{17}$ R. D. Flender, op. cit. pp. $228 \mathrm{~s}$.

${ }^{18}$ Quiero expresar mi agradecimiento en el estudio de las partituras de Abdías a Francisco Javier Lara Lara.

19 S. Sadie (ed.), The New Grove Dictionary of Music and Musicians, London, 1980, p. 626. 
pues probablemente se convirtió en Italia ${ }^{20}$. Según esto, fue en su tierra natal donde empezó a acercarse a la cultura judía. También cabe la posibilidad de que plasmara música de los judíos de Djerba, incluso pudo tener la intención de conservarla en sus partituras. Y desde luego es plausible que tenga presente en su música las normas específicas del canto gregoriano, de las que sería conocedor dada su experiencia como monje. Con todo, el estudio de la música de Abdías refleja una interesante relación entre la cultura cristiana y judía. Por tanto, sería un error ceñir estos manuscritos a una sola influencia.

Sin embargo, el estudio de este personaje se ha realizado casi exclusivamente desde el punto de vista judío. Al igual que Abdías sintetiza estas tradiciones en su notación, como he manifestado en líneas anteriores, también lo hace en sus textos.

Abdías presenta en su autobiografía una cita del profeta Joel. En lugar de presentarla en hebreo, aparece en latín transcrita a caracteres hebreos. Analizaremos la posibilidad de que Abdías pretendiera contraponer su conversión al judaísmo con su ordenación como monje cristiano a través de la transcripción de la cita de Joel.

\section{ABDÍAS, EL PROSÉLITO NORMANDO}

Actualmente los investigadores coinciden en que el autor de las partituras con notación neumática y letra hebrea encontradas en la Genizah del Cairo es GiovanniAbdías, el prosélito normando ${ }^{21}$. Conocemos a este personaje únicamente a través de los documentos encontrados en esta Genizah ${ }^{22}$ : la carta de recomendación de un rabino de Alepo, la autobiografía de Abdías y un libro de plegarias escrito por Abdías.

En 1930 Jacob Mann identificó los tres manuscritos de Abdías. Gracias a ello se supo que Abdías provenía de una familia noble normanda, su carrera eclesiástica, su conversión al judaísmo y su estancia en medio oriente ${ }^{23}$.

Abdías es descendiente de una importante familia normanda que se implicó en la conquista del sur de Italia ${ }^{24}$. El hecho de que los normandos marcharan al sur de Ita-

\footnotetext{
${ }^{20}$ Véase J. Holo, «Jewish communities and personalities within Ovadiah's Chronicle», en A. De Rosa y M. Perani (coords.), op. cit. pp. 161ss.

${ }^{21}$ Véase N. Golb, «Obadiah the Proselyte: Scribe of a Unique Twelfth-Century Hebrew Manuscript Containing Lombardic Neumes», en The Journal of Religion vol. $45 \mathrm{n}^{\circ} 2$ (abril 1965), pp. 153-156; A. Friedlander, «Discovery of an Ancient Hebrew Manuscript Containing Neums», en The Musical Times Publications vol. 62 nº 937 (marzo 1921), pp. 170-172; A. Scheiber, «Obadiah the Norman proselyte, notator of the first known Hebrew melody» en Tarbiz vol. 34 n4 (julio 1965), pp. 366-371; N. Allony, «Me-hammahzôr le-ovadyah», en Sinay vol. 57 (abrilmayo 1965), pp. 43-55; M. Perani, «Rilievi paleografici sulla scrittura di Ovadiah da Oppido», en A. De Rosa y M. Perani (coords.), op. cit. pp. 119-123; I. Adler, «Les chants synagogaux notés au XIIe siècle (ca. 1103-1150) par Abdias, le prosélyte normand», en Revue de Musicologie, t. 51e nº1er (1965), p. 26.

22 A. Scheiber, «Der normannische Proselyt Obadja, der Aufzeichner der ersten hebräischen Melodie», en Studia Musicologia Academiae Scientiarum Hungariae t. 8 (1966), p. 176.

${ }^{23}$ P. Mancuso, «I manoscritti e I frammenti della Cronaca di Ovadiah», en A. De Rosa y M. Perani (coords.), op. cit. p. 110.

${ }^{24}$ Véase A. Giganti, «Oppido normanna e la famiglia di Giovanni-Ovadiah», en A. De Rosa y M. Perani (coords.), op. cit. pp. 13-23.
} 
lia se inscribía en un proyecto organizado por las dos potencias que dirigían entonces el occidente cristiano: el Papa y el Emperador. Se intentaba poner término a la ofensiva musulmana, latente en el sur de la península, y al mismo tiempo hacer retroceder la potencia de los griegos, restablecida en Apulia pero aún poco eficaz contra los musulmanes y demasiado amenazadora para los intereses que Roma y el Imperio Germánico habían defendido siempre en esas tierras.

En este proyecto ocupará un papel importante la familia de Abdías. Giovanni-Abdías era hijo de Drogo y nieto de Tancredo, de la familia Hauteville. Tenemos la suerte de que historiadores contemporáneos a los colonos normandos de esta familia han restituido al detalle su historia ${ }^{25}$. La descendencia del ilustre Tancredo era muy numerosa, tanto que pese a contar en su haber con una gran fortuna, no era suficiente para asegurar el porvenir de toda ella. Geoffroi Malaterra relata el éxodo de doce caballeros, hijos del ilustre Tancredo. Éste mantenía amistad con el duque de Normandía, quien habría podido facilitar a sus hijos un puesto al servicio de un obispo o en un monasterio. Pero decidieron mantenerse como caballeros. Para ello, tras abandonar su patria, buscaron beneficios a través de las armas hasta llegar al fin a Pouille, provincia de Italia. Tras muchas vicisitudes, la mayoría de los hijos de Tancredo se estableció en el sur de Italia, donde conseguirá más honores de los que habría podido lograr en su lugar de origen. Entre los hijos de Tancredo destacaron: Guillermo, Roberto Guiscardo, Roger y Drogo, este último será el padre de Abdías.

Drogo se casó con la hija del príncipe Guaimaro IV de Salerno. Drogo alcanzará tanta importancia como el propio príncipe de Salerno, el príncipe más importante de toda Italia, incluso llegará a recibir el mando de toda Apulia ${ }^{26}$.

Drogo, padre de Abdías, fue asesinado el 10 de agosto de 1051. El asesino de Drogo pudo estar relacionado con las hordas de los bizantinos, dirigidos por Argiro, quien parecía haber planeado la erradicación de todos los normandos en un solo día. Es muy posible también la participación de la población del lugar, que estaba resentida por los elevados impuestos a los que les sometía el conde Drogo ${ }^{27}$.

Pronto florecería el nuevo centro de Opido. Mientras, Abdías, hijo de Drogo, era instruido por numerosas personalidades venidas de todas partes del mundo ${ }^{28}$. La «nobleza» de su familia y el poder político que ostenta hacían de él un personaje relevante destinado a perpetuar un poderoso linaje. Pero su conversión cambiará ese destino.

En su autobiografía, Abdías muestra tres cuestiones que le llevarían a su conversión. Aparte del hecho de que está escrita en hebreo, el primer elemento narrativo que capta la atención de los lectores es el nacimiento de Abdías. Menciona el nombre de su padre, su madre y su hermano. Explica que su madre, María, tuvo en el mismo día dos hijos, y hace hincapié tanto en que Abdías era el menor de los gemelos como en la di-

${ }^{25}$ Véase H. Taviani-Carozi, La terreur du monde. Robert Guiscard et la conquête normande en Italie, Paris, 1996, pp. 49-55.

${ }^{26}$ Idem, pp. $177 \mathrm{~s}$.

${ }^{27}$ A. Giganti, op. cit. p. 17.

${ }^{28}$ Idem, pp. 22s. 
ferencia de carácter de ambos hermanos. Esto trae a la mente un tema bien conocido por los lectores judíos. En la descripción de Abdías de su nacimiento y juventud, su destino judío parece presagiado por ser el gemelo más joven. Roger, su hermano mayor, siguió una carrera militar, mientras que Giovanni, tanto por temperamento como por orden de nacimiento, dirigió su vida al estudio y a ser clérigo. Hace referencia a la historia bíblica sobre Jacob y Esaú, según la cual Jacob, antepasado epónimo de los israelitas, es paralelo a Giovanni-Abdías dado que ambos eran los menores de los gemelos y los más «intelectuales», mientras que Roger, el mayor, más atlético, recuerda a Esaú o Edom, quien para los judíos medievales se asocia con los cristianos europeos. Según Holo, este paralelo bíblico debió verlo Abdías ${ }^{29}$.

La segunda cuestión hace referencia al arzobispo de Bari. Abdías habla de la conversión al judaísmo del arzobispo de $\mathrm{Bari}^{30}$. Cuenta que escuchó la historia de Andrés, arzobispo de Bari, cuando era un niño. Abdías debía tener en el momento de la conversión de mencionado arzobispo unos diez años de edad. Es precisamente gracias al testimonio de Abdías que hoy conocemos la historia de la conversión del arzobispo de Bari. Las fuentes eclesiásticas informan sólo de forma muy lacónica sobre él, se limitan a mencionar su ordenación como arzobispo en 1062, sus viajes a Constantinopla en 1066, y el final de su mandato (y supuesta muerte) en $1078^{31}$. Abdías cuenta cómo Andrés se convirtió al judaísmo y tuvo que huir de sus ex correligionarios para salvar su vida. Expone después cómo el arzobispo marchó al Cairo, donde vivió hasta su muerte. Comenta Abdías que la noticia de la conversión del arzobispo causó un gran impacto. Según él, el efecto fue tal que otros siguieron su mismo camino, pero de estos personajes secundarios no han sobrevivido documentos. Abdías hace constar que este hecho tuvo repercusión en el ambiente erudito de Bizancio y de Roma, incluso llegó a la sede papal. Según Golb ${ }^{32}$ no hay razón objetiva para dudar de la veracidad y precisión de lo contado por Abdías sobre la conversión de Andrés. Se deduce pues que esta historia le causó a Abdías una fuerte impresión.

Finalmente, mencionaré una última cuestión: el sueño de Abdías. Abdías relata un sueño, o tal vez una pesadilla, que tuvo cuando era aún un niño. El sueño acontece en torno a una misa de connotaciones negativas, pues según sus palabras le estaba «corrompiendo». Cuenta que soñó que estaba oficiando misa en la iglesia principal de Opido, cuando miró arriba y observó a un hombre que estaba en pie a su derecha, frente al altar. Este hombre le dijo: « ¡Giovanni!»"33.

La liturgia que se está oficiando en su sueño es negativa, pues le está corrompiendo. El hecho de que un hombre a su derecha junto al altar le llamara «Giovanni» muestra

\footnotetext{
29 J. Holo, op. cit. p. 151.

30 Véase C. Colafemmina, «La conversione al giudaismo di Andrea, arcivescovo di Bari: una suggestione per Giovanni-Ovadiah da Oppido», en A. De Rosa y M. Perani (coords.), op. cit. pp. 55-65.

31 J. Holo, op. cit. p. 152.

${ }^{32}$ N. Golb, «La conversione al giudaismo nel suo contesto storico, con particolare riferimento ai documenti della Genizah del Cairo», en A. De Rosa y M. Perani (coords.), op. cit. p. 78.

${ }^{33}$ Véase Idem p. 261; A. Büchler, «Obadyah the Proselyte and the Roman Liturgy», en Medieval encounters vol. 7 nos 2-3 (2001), p. 171; A. M. Somekh, op. cit. p. 190.
} 
que Giovanni estaba formando parte de esa liturgia, cerca del altar. Por desgracia se desconoce que más palabras le dirige por el estado en el que se ha conservado el texto. Según Holo, el propio Giovanni aparece en este sueño como el sacerdote que preside en la iglesia ${ }^{34}$.

Abdías menciona este sueño como un detonante de su conversión. Explica que guardó este sueño en su memoria y sólo logró interpretarlo tras haber conocido el judaísmo. Es posible que Abdías considerara la mención de su nombre una llamada de atención, como si la persona que se dirige a él le estuviera advirtiendo que la religión que profesaba estaba sumida en un error ${ }^{35}$. Según su testimonio, a partir de este sueño Giovanni pasó a considerarse definitivamente Abdías.

Tras su conversión, Abdías contó en su haber con una carta de recomendación de un rabino de Alepo, que por fortuna también se conservó en la Genizah del Cairo. El nombre de este rabino es Baruk ben Isaac ${ }^{36}$, a quien conocemos a través de otras cartas de la Genizah. Era la principal autoridad rabínica de Alepo a comienzos del siglo XII. Es precisamente entonces cuando escribe la carta a favor de Abdías. Vemos pues que la suya no era una recomendación cualquiera. El ser una eminencia puso en contacto a Baruk ben Isaac con los estudiosos de los alrededores de la región, como deja explícito en su correspondencia, este amplio acceso a la información le otorga un peso particular a sus observaciones. Lo que más destaca es su poética descripción de la situación de los judíos en la Tierra de Israel durante la Primera Cruzada. Sabemos por otras fuentes también que las cruzadas les trajeron una gran destrucción que hizo disminuir a la comunidad judía de Palestina, por lo que parece probable que Abdías fuera precisamente uno de los judíos desplazados para los que Baruk escribió su carta. Como en una carta de recomendación tradicional, en este texto establece la buena fe de su carrera, describe la conversión de Abdías y apunta su legalidad. Baruk caracteriza la conversión de Abdías en términos intelectuales y la relaciona además con la fuerza espiritual ${ }^{37}$.

Efectivamente Abdías era un hombre culto. Recordemos que fue instruido en su infancia por numerosas personalidades académicas venidas de todas partes del mundo. Y no olvidemos su posterior formación como clérigo. Su afán por el conocimiento era incesante. Sabemos que Abdías llegó a Bagdad en $1110^{38}$. Entró en contacto con

\footnotetext{
${ }^{34}$ J. Holo, op. cit. p. 154.

35 Abdías en su sueño hace referencia al cristianismo como algo negativo. Posiblemente no se refería al cristianismo en su totalidad, sino a los recientes aconteceres relacionados con él, como las cruzadas (a las que critica expresamente en su autobiografía) y las disputas teológicas internas en el sur de Italia. Abdías no parece renegar por entero de su pasado, sino que parece entender su conversión como parte de un crecimiento personal, no como una afrenta a su pasado cristiano. (Véase A. M. Somekh, op. cit. p. 191). Tampoco reniega de su formación cristiana en sus partituras, no sólo por el hecho de emplear neumas gregorianos, sino por respetar reglas compositivas gregorianas, tales como la de evitar los intervalos de quinta disminuida. (Véase I. Adler, (1965), op. cit. pp. 45ss.).

36 Véase J. Holo, op. cit. pp. 160ss.

37 Idem, p. 153.

${ }^{38}$ Para vislumbrar cómo pudo ser el largo viaje de Abdías, Kedar (B. Z. Kedar, «The voyages of GiuànOvadiah in Syria and Iraq and the enigma of his conversión», en A. De Rosa y M. Perani (coords.), op. cit. pp. 133-147) propone el estudio de un viaje similar del que tenemos muchos detalles. Es un viaje por mar de Apulia a levante ese mismo año, 1102. Es el narrado en escritura latina por el peregrino anglosajón Saewulf.
} 
Isaac, la cabeza de la academia. Éste se comprometió incluir a Abdías en la labor de estudiar la Biblia hebrea junto con los huérfanos que estaban bajo la tutela de la comunidad. Aprendería con ellos el alefato y llevaría a cabo estudios bíblicos, y tal vez se acercaría a los estudios talmúdicos, más complejos, que ocupaban a los jóvenes. Según Scheiber, Abdías destacó en todas sus actividades y logró escribir en hebreo bíblico con un estilo sorprendentemente bueno ${ }^{39}$.

$\mathrm{Su}$ experiencia demuestra asimismo cómo un neófito no tiene por qué ser un experto en la ley antes de convertirse; un no judío puede entrar en la alianza mediante su práctica de la religión básica y el compromiso de desarrollar una vida judía con el transcurrir del tiempo ${ }^{40}$.

La avidez de conocimiento de Abdías queda reflejada también en su elección de los versículos para la partitura del ms. Cambridge: Prov. 3, 13 y Job 5, 17; donde se ensalza la sabiduría.

Abdías no aporta datos sobre su vida familiar en Egipto. Cabe la posibilidad de que tuviera un hijo, llamado Elías ${ }^{41}$. Probablemente Abdías terminó sus días en el Cairo, donde escribió sus manuscritos.

En definitiva, cuando la apostasía de Andrés, arzobispo de Bari, llegó a ser conocida, tal vez en 1073, Giovanni tenía diez años ${ }^{42}$. Si imaginamos a este niño, de inclinación intelectual y gran curiosidad, el rumor escandaloso sobre la conversión de Andrés pudo despertar en él dudas y ansias de búsqueda religiosa ${ }^{43}$. La época que vivió fue tremendamente convulsa. Giovanni era sobrino de Roberto el Guiscardo, un temido conquistador normando cuyo epitafio reza: «Aquí yace Roberto el Guiscardo, terror del mundo»; hijo de Drogo, asesinado cuando Giovanni era un niño; testigo del horror de las cruzadas, temeroso de la llegada del fin de los días (como veremos), un monje sabio que inició una arriesgada búsqueda. La inició con una pesadilla y ansiaba terminarla con un sueño que podría verse materializado en la promesa que esperan los judíos, la llegada del Mesías que restaurará la paz. Ése parecía ser el sueño de Abdías, sueño que comenzó cuando aún respondía al nombre de Giovanni.

\section{LA PROFECÍA DE JOEL}

Encontramos en la autobiografía de Abdías referencias relacionadas con la liturgia cristiana. S. D. Goitein, el decano de los estudios de la Genizah del Cairo ${ }^{44}$, descubrió que un pasaje de la autobiografía en el que habla de su conversión al judaísmo

\footnotetext{
${ }^{39}$ A. Scheiber, (1966), op. cit. p. 177.

${ }^{40}$ J. Holo, op. cit. pp. $156 \mathrm{~s}$.

${ }^{41}$ Scheiber, (A. Scheiber (1966), op. cit. p. 59) encontró además un manuscrito que forma parte de la Bodleian Library donde aparece un poema atribuido a Elías, a quien se conoce como el hijo de Abdías, y que podría completar la letra de una de las partituras de Abdías.

${ }^{42}$ C. Colafemmina, op. cit. p. 60.

43 J. Holo, op. cit. p. 153.

${ }^{44}$ B. Z. Kedar, op. cit. p. 142.
} 
aparece una cita en latín del profeta Joel transcrita a caracteres hebreos. En 1954, Goitein publicó este fragmento de la autobiografía de Abdías ${ }^{45}$. Este pasaje de la profecía de Joel 3, 28-32 dice así:

Sol convertetur in tenebras et luna in sanguine; antequam veniat dies Domini magnus et horribilis ${ }^{46}$.

Cabe preguntarse cuál es el motivo de que Abdías escribiera esta profecía en latín transcrita en caracteres hebreos, en lugar de escribirla directamente en hebreo, y más cuando está inserta en su autobiografía, como sabemos escrita en hebreo.

Este pasaje de Joel se emplea en la liturgia cristiana precisamente en las ordenaciones, por lo que Abdías parece relacionar esta profecía con dos momentos de implicación religiosa en su vida: su ordenación como monje cristiano y su conversión al judaísmo.

Esta profecía, tal y como expone Büchler ${ }^{47}$, aparece entre las primeras lecturas del «Sábado de Témporas ${ }^{48}$ ». Hablamos pues de Pentecostés, que conmemora el acontecimiento del descenso del Espíritu Santo relatado por Pedro (He 2, 1-21). A esta celebración volveré más tarde.

Este sábado era uno de los cinco días en que tenían lugar las ordenaciones cristianas. Es posible pues, como apunta Büchler, que Abdías hubiera escuchado esta profecía en su propia ordenación como monje cristiano. Es muy interesante ver cómo Abdías, al relatar su conversión al judaísmo en la autobiografía, apunta esta profecía de Joel. Pensemos además que Abdías escribió su biografía unos veinte años después de su conversión. Según Goitein ${ }^{49}$, la versión en latín debió tener una tremenda influencia en él por su dramático contenido. Es probable que Abdías pretenda contraponer su conversión al judaísmo con su ordenación como monje cristiano. No parece casual que eligiera este fragmento entre todos los que se leen durante el Sábado de Témporas. Veamos la lectura de Joel durante el sábado de témporas en su versión en latín, que es como debió escucharla Abdías en su ordenación:

Léctio Joélis Prophétae, 28-32. Haec dicit Dóminus Deus: Effúndam Spiritum meum super omnem carnem: et prophetábunt filii vestry et filiae vestrae. Senes vestry sómnia somniábunt, et iúvenes vestry visions vidébunt. Sed et super servos meos et ancillas in diébus illis effúndam Spiritum meum. Et dabo prodigia in caelo et in terra, sanguine et vapórem fumi. Sol convertetur in ténebras et luna in sanguine: ántequam véniat dies Dómini magnus et horribilis. Et erit: omnis qui invocáverit nomen Dómini, salvus erit ${ }^{50}$.

${ }^{45}$ A. Büchler, op. cit. p. 166.

${ }^{46}$ «El sol se convertirá en tinieblas y la luna en sangre antes de que venga el día grande y terrible de Dios».

${ }^{47}$ A. Büchler, op. cit. p. 167.

${ }^{48}$ Segundas Témporas.

${ }^{49}$ B. Z. Kedar, op. cit. p. 143.

50 «Lección del Profeta Joel. Esto dice el Señor Dios: Derramaré mi espíritu sobre toda carne, y profetizarán vuestros hijos y vuestros ancianos tendrán sueños, y vuestros mozos verán visiones, y aún sobre vuestros 
Si tomamos este fragmento de la profecía, la lectura cristiana parece clara en la celebración de Pentecostés. Pedro ve también el cumplimiento de esta profecía a partir del día de Pentecostés $(H e 2,16)^{51}$. De hecho, en la liturgia de Pentecostés, tras la lectura de la profecía de Joel encontramos el texto siguiente:

«Abrásenos, Señor, el Espíritu Santo con aquel fuego que nuestro Señor Jesucristo trajo a la tierra y ansía ver encendido: Él, que contigo vive y reina, en unidad del mismo Espíritu Santo».

Si prestamos atención al final de la lectura del profeta Joel para el «Sábado de Témporas», Joel 32, veremos que dice algo que parece clave:

«Y todo el que invocare el nombre del Señor será a salvo; porque en el monte Sión y en Jerusalén estará el grupo de salvados, como ha dicho el Señor, y entre los supervivientes estarán los que llame el Señor».

El fragmento muestra una clara lectura judía, la alusión al esperado fin de los días y la llegada de su ansiado Mesías. La exégesis cristiana del pasaje de Joel es ambigua: algunas partes parecen referirse al pasado, otras al futuro ${ }^{52}$. En el caso de la lectura judía, se refiere claramente al futuro.

\section{ABDÍAS Y LA VISIÓN ESCATOLÓGICA DE LA PROFECÍA DE JOEL: LA CUESTIÓN MESIÁNICA}

Giovanni eligió el nombre de Abdías ${ }^{53}$, esto no parece casual dada la vinculación escatológica con este nombre, también por ser este profeta un prosélito y por su relación con la historia de Jacob y Esaú.

Según el profeta Abdías, el triunfo de Israel supondrá su restauración en el futuro mesiánico.

Y es que Giovanni-Abdías estuvo influenciado por corrientes mesiánicas ${ }^{54}$. Uno de los aspectos más fascinantes de la biografía de Abdías es su relato sobre tres falsos mesías. Proporciona interesantes cuestiones tanto sobre el fervor mesiánico del momento como sobre su propia relación con ello, que culmina con su encuentro personal con el caraíta Salomón ben Rugi, en Banias, el único a quien Abdías conoció

\footnotetext{
siervos y siervas derramaré mi Espíritu en aquellos días y haré prodigios en el cielo y pondré en la tierra sangre y fuego y columnas de humo. Y se cubrirá de tinieblas el sol y de sangre la luna, antes de que venga el día grande y terrible del Señor, y todo el que invocare el nombre del Señor será a salvo».

${ }^{51}$ Pedro presenta además la profecía de Joel en He 2, 17-21.

${ }^{52}$ B. Z. Kedar, op. cit. p. 143.

${ }^{53}$ De todos los escritos proféticos de la Biblia hebrea, el del profeta Abdías, redactado en torno al año 550 aproximadamente, es el más breve. En él se critica con ferocidad a Edón por su actitud con respecto a Judá. Edón puede ser interpretado simbólicamente como todos los enemigos de Israel.

${ }^{54}$ J. Holo, op. cit. pp. 157 ss.
} 
personalmente. Esos falsos mesías se ganaron el desprecio de Abdías dado que no sólo frustraron las esperanzas de sus correligionarios, sino que también provocaron burlas por parte de la población local hacia los judíos. La preocupación de Abdías con respecto a estas expectativas mesiánicas responde, no sólo al poder de esos movimientos sobre las comunidades judías, sino también a su propio interés en la cuestión, quizás en reacción al mesianismo cristiano.

Su participación personal en la cuestión mesiánica resulta más evidente en su relato sobre el caraíta Salomón, el único personaje de pretensiones mesiánicas al que Abdías conoció personalmente. Según la autobiografía, mantuvieron una discusión en la que Abdías refutó las pretensiones mesiánicas de Salomón ${ }^{55}$.

Las cuestiones escatológicas también ocuparon lugar destacado en el cristianismo del momento y podemos encontrar vinculaciones entre ambas tradiciones.

El Libro de Zorobabel ${ }^{56}$, un libro pseuoepigráfico de comienzos del Medioevo, de suma importancia, expone cómo el Mesías será precedido por un rey satánico de Roma, que conquistará el mundo entero. Se escribirá una abundante literatura a partir de esta obra dedicada a descubrir los signos (otot mashiaj) que anuncien la llegada de la era mesiánica ${ }^{57}$. También el cristianismo presenta signos que anuncian el apocalipsis, pues la tensión escatológica es común en la víspera de la Primera Cruzada entre cristianos y judíos. Tomemos por ejemplo los eclipses, mencionados tanto en crónicas cristianas como judías. Prawer y Gold sugieren que Abdías interpretó «(se cubrirá) de sangre la luna» con los eclipses de 1095 y $1096^{58}$. Hay crónicas latinas que hablan de la aparición de cuerpos celestiales. En efecto, un cronista de Apulia, contemporáneo de Abdías, habla de la caída de muchas estrellas y de que la mitad del cielo se volvió rojo ${ }^{59}$. En la primera parte de su trabajo De diversitate temporum, Alberto de Metz ${ }^{60}$ describe un «terrible cometa que desprendía llamas» que apareció en el cielo sobre Alemania y que, según él, aterrorizó a todos aquellos que lo vieron. El cometa apareció en 1005, tres años después de la coronación de Enrique y, según Alberto, «fue seguido por el hambre y la muerte en todo el mundo» ${ }^{61}$.

Kedar añade un tratado escatológico que gozó de gran popularidad en la Europa católica como posible influencia en la visión apocalíptica de Abdías: el Apocalipsis de Pseudo-Methodius ${ }^{62}$. Originalmente estaba escrito en siríaco en la segunda mitad del siglo VII y probablemente fue traducido al griego durante la segunda mitad del siglo VIII y una década después, en alguna parte del reino merovingio, del griego al latín. El tratado aparece en unos doscientos veinte manuscritos, por lo menos veintiuno de ellos son anteriores al año 1100 y uno de ellos es propiedad de la aba-

\footnotetext{
${ }^{55}$ Véase A. M. Somekh, op. cit. pp. 175-194; J. Holo, op. cit. pp. 149-164.

56 A. Alba, «El Libro de Zorobabel», en Sefarad (2001) 61/2, pp. 243-258.

${ }^{57}$ M. J. Cano y M. A. Espinosa, Historia y cultura del pueblo judio, Granada, 2007, p. 67.

58 A. Büchler, op. cit. pp. 167ss.

${ }^{59}$ B. Z. Kedar, op cit. p. $143 \mathrm{~s}$.

${ }^{60}$ N. Golb, (2004), op. cit. pp. 70ss.

61 Idem, p. 70.

${ }^{62}$ Véase: B. Z. Kedar, op. cit. pp. 145ss.
} 
día de Cava, a unos cien kilómetros al noreste de Opido. En la parte profética de este tratado leemos que cerca del fin de $\operatorname{los}_{\text {días }}{ }^{63}$ el Anticristo mostrará muchos signos y maravillas y:

«convertit enim sol in tenebris (sic) et lunam in sanguinem» ${ }^{64}$.

Ernst Sackur, el primer editor del tratado, advirtió en 1898 que está parafraseando Joel 2: 31. Kedar explica que es posible que Abdías leyera este texto cuando aún era cristiano. Según Kedar caben dos posibilidades relacionadas con la influencia que pudo ejercer sobre Abdías la lectura del tratado:

La primera supone que Giovanni entiende que Joel está hablando de la era mesiánica. Los eclipses de 1096 significarían que Dios llevará a los gentiles al Valle de Josafat y les juzgará por sus maldades contra Israel, quien a partir de entonces prosperará en Jerusalén y Judea bajo la protección de Dios. Abdías entendería según esto que la Primera Cruzada será el detonante que conllevará al anunciado Juicio Final y que pronto vendría la liberación de Israel. Así, decidió convertirse al judaísmo. Según esta interpretación, su conversión estuvo influenciada entre otras cosas por la lectura del Joel según Pseudo-Methodius.

La segunda posibilidad consiste en que la conversión fuera provocada por la profecía de Pseudo-Methodius en sí misma. Según Pseudo-Methodius, la oscuridad del sol y la luna es obra del Anticristo, que entra en Jerusalén y «se sienta en el Templo como Dios, aunque es un hombre, nacido del esperma de un hombre y del útero de una mujer, un descendiente de la tribu de Dan». Consecuentemente, Abdías tal vez contempló la Primera Cruzada, las persecuciones de los judíos en Europa y el asentamiento de los cristianos en Jerusalén como obras del Anticristo. Según Pseudo-Methodius, el dominio del Anticristo terminaría con el Segundo Advenimiento, la aniquilación del Anticristo y el triunfo del Justo. La combinación de la lectura de Joel y Pseudo-Methodius llevaría según esta segunda posibilidad a Abdías a creer que al establecimiento del poder franco en oriente le seguiría la derrota de los francos y la liberación de Israel.

Sin embargo, no es necesario que Abdías tuviera constancia del Apocalipsis de Pseudo-Methodius. Es más, si esta obra hubiera tenido en él un impacto tal, cabe suponer que la habría mencionado en su autobiografía. Abdías pudo hacer una lectura judía de la profecía de Joel sin la necesidad explícita de haber leído a Pseudo-Methodius. Incluso de haberlo leído, tal vez le influyó, pero parece muy probable que la razón de elegir esta profecía se relacione en realidad con un hecho muy importante en su vida, como ya mencioné: su ordenación como monje cristiano. Como veíamos en líneas anteriores, la profecía de Joel aparece entre las primeras lecturas del «Sábado de Tém-

${ }^{63}$ Hace referencia a los últimos días del mundo conocido antes del triunfo del Mesías sobre el mal. Véase E. Baroukh y D. Lemberg, Enciclopedia práctica del judaísmo, Barcelona, 1995, pp. 136s; p. 216.

${ }^{64}$ B. Z. Kedar, op. cit. pp. $146 \mathrm{~s}$.

${ }^{65}$ La fiesta de Shavu'ot celebra el don de la Torah, representa pues el encuentro entre Dios, la Torah e Israel. «Para los judíos, la Torah en sentido estricto significa Pentecostés». A. C. Avril y D. de la Maisonneuve, Las fiestas judias, Navarra, 2001, p. 40. 
poras», uno de los cinco días en que tenían lugar las ordenaciones cristianas. De esta manera puede contraponer su ordenación como monje cristiano con su conversión al judaísmo. Como hemos visto, consigue de esta manera vislumbrar uno de los posibles motivos de su conversión: el creer cercano al Juicio Final, bajo la lectura judía.

\section{EL JUDAÍSMO EN GIOVANNI-ABDÍAS Y LA FIESTA DE PENTECOSTÉS}

Parece existir un paralelismo entre recibir la Torah en el judaísmo y recibir la llama del Espíritu Santo en el cristianismo ${ }^{65}$. Recordemos que Abdías incluyó la profecía de Joel en su autobiografía. Presenta la profecía de Joel en latín transcrita en caracteres hebreos, cuando podría haberla escrito en hebreo, más aún si tenemos en cuenta que su autobiografia está escrita en su totalidad en hebreo. Esta referencia al latín parece una alusión a su pasado cristiano. La lectura de la profecía de Joel, como comentamos con anterioridad, se lee el «Sábado de Témporas», uno de los cinco días en los que se llevaban a cabo las ordenaciones cristianas. Con esta profecía hace referencia a Pentecostés, fiesta que enmarcó su ordenación como monje cristiano. Esta fiesta coincide en el judaísmo con la celebración del recibimiento de la Torah. Abdías, al convertirse al judaísmo, recibió simbólicamente el conocimiento de la Torah. Tal vez pues quiso contraponer intencionadamente su nombramiento como monje cristiano con su conversión al judaísmo.

Tanto en el judaísmo como en el cristianismo, la teofanía del Sinaí simboliza un comienzo. La teofanía del Sinaí marca para Israel el verdadero comienzo de su historia $^{66}$. Con respecto al cristianismo, existe la posibilidad de que Lucas, al describir el nacimiento de la Iglesia cristiana el día de la fiesta de Pentecostés (He 2), haya utilizado las tradiciones judías de su época sobre la teofanía del Sinaí ${ }^{67}$.

Además de ello, Abdías pudo haber hecho alusión a Pentecostés por más cuestiones. En varias ocasiones en su biografía, Abdías muestra su sensibilidad hacia los judíos y su defensa, que le conduce a su propia conversión. Recordemos que Giovanni cambió su nombre por el del profeta Abdías, quien vaticinó que Dios castigaría con ferocidad a quienes hicieran daño a los judíos. Podemos verlo en Is $62,8 \mathrm{~s}$, donde relaciona esta fiesta con la liberación de cualquier poder ocupante ${ }^{68}$. Recordemos también que las cruzadas se proponían dominar la «Tierra Santa», acto que a Abdías le parecía no tener sentido, así lo muestra en su autobiografía.

En el contexto de defensa de los judíos por parte de Abdías, aludir a la fiesta de Pentecostés puede además otorgarle fuerza dado su contenido político ${ }^{69}$. Simbólica-

\footnotetext{
${ }^{66}$ J. Potin, La fête juive de la Pentecote, Paris, 1971, p. 299.

${ }^{67}$ Idem p. 300.

${ }^{68}$ Idem p. 36.

${ }^{69}$ Pensemos además que Abdías presenta en sus partituras dos piyyutim: Mi'al har horeb y Wa-eda'mah. El piyyut mantiene la tradición bíblica, no se transcriben los términos griegos, sino que se traducen por un equivalente auténticamente hebreo. Esto responde a un carácter nacionalista que conduce a evitar palabras extranjeras en el vocabulario (A. Sáenz-Badillos, Historia de la lengua hebrea, Barcelona, 1988, pp. 210s). Precisamente, parece que el piyyut Mi'al har horeb estaba destinado a la celebración de Simhat Torah.
} 
mente es una fiesta que goza de suma importancia, pensemos por ejemplo en que según la tradición, David nació y murió el día de $s h a v u^{\prime} t^{70}$; o en que Flavio Josefo describe en Guerra II, 3, 1 y Ant. Jud. XVII, 10, $2^{71}$ una sublevación popular de los judíos contra Sabino el día de Pentecostés. La finalidad es pues menos religiosa que política. De hecho, Filón de Alejandría dice que «Pentecostés es la más política de las fiestas» en De spec. Leg. I, $183^{72}$. Recordemos además que después de la destrucción del Templo, cuando los fariseos pudieron imponer su calendario y sus conceptos teológicos, la lectura de los diez mandamientos ${ }^{73}$ fue desplazada a la fiesta de Pentecostés. Esto se hizo a causa del significado como fiesta de la Alianza y tal vez también como fiesta nacional y patriótica ${ }^{74}$. Como advierte Potin ${ }^{75}$, tal vez habría que sospechar que Pentecostés ha revestido un carácter bastante político y patriótico, lo que concuerda con una fiesta de renovación de la Alianza, nacida precisamente en una atmósfera de reacción violenta contra las amenazas políticas y religiosas de las que el judaísmo era objeto. Este ambiente hostil hacia los judíos se dio también durante las cruzadas, hecho que consideró Abdías como vituperable. Tanto es así que, por ejemplo, cuando Abdías menciona en el texto las persecuciones contra los judíos de Bagdad, su estilo cambia y ya no es un mero cronista, sino que parece removerse su fuero interno, deja traslucir su experiencia personal ${ }^{76}$.

Es posible establecer otro paralelismo entre la teofanía del pueblo de Israel y el día de Pentecostés. La teofanía llevó a Israel a un nuevo estado de purificación donde quedó abolido el mal del pasado. El día de Pentecostés implica algo semejante para los cristianos al recibir las lenguas de fuego ${ }^{77}$. Así pues, este significado de purificación habría sido interpretado fácilmente por Abdías dada su experiencia cristiana y judía. Es posible de este modo que Abdías entendiera su conversión como una purificación.

Todos estos elementos muestran cómo esta doble tradición se fusiona en la figura de Abdías.

\section{CONCLUSIÓN}

La Genizah del Cairo contaba en su haber unos manuscritos con notación gregoriana y escritura hebrea que constituyen un caso excepcional en la historia de la música. En sus manuscritos con notación musical se conjugan las tradiciones cristiana y judía. Esta Genizah también guardaba varios documentos que han hecho posible el

${ }^{70}$ A. C. Avril y D. de la Maisonneuve, op. cit. p. 45.

${ }^{71}$ J. Potin, op. cit. p. 136.

${ }^{72}$ Idem.

${ }^{73}$ En la tradición farisea, el don de la Torah ha sido primero evocado en el cuadro de la neomenia del primero de Tishri, fiesta donde ya antes del establecimiento de Rosh ha-shana se anunciaba el juicio de Dios sobre la humanidad.

${ }^{74}$ J. Potin, op. cit. pp. $155 \mathrm{ss}$.

75 Idem.

76 J. Holo, op. cit. p. 156.

77 J. Potin, op. cit. pp. 304s. 
descubrimiento del autor de tales partituras, Abdías, el prosélito normando, y de su intensa vida. Este personaje, de erudito fervor, escribió su propia biografía en hebreo.

En la autobiografía aparece una cita del profeta Joel en latín pero transcrita a caracteres hebreos. Esta profecía aparecía en su origen en hebreo, pues como sabemos forma parte de la Biblia hebrea. Además, Abdías inserta esta profecía en su autobiografía, que presenta en hebreo. ¿Entonces por qué escribe esta profecía en latín transcrita a caracteres hebreos, en lugar de escribirla directamente en hebreo? ¿Qué le conduce a escoger esta profecía, de contenido escatológico?

Es muy probable que Abdías escribiera esta profecía en latín en alusión al cristianismo, y que lo hiciera transcrita en caracteres hebreos para relacionarla a su vez con el judaísmo. Abdías mostró ser conocedor de ambas tradiciones, por haber pertenecido a ambas y por haberlas estudiado en profundidad.

La profecía se lee en el contexto de la fiesta cristiana de Pentecostés, y además durante uno de los cinco días en los que tiene lugar las ordenaciones cristianas. Pentecostés coincide con la fiesta judía de shavu'ot. Pensemos además que esta profecía presenta contenido escatológico. En esta época, en las tradiciones judía y cristiana las cuestiones escatológicas ocuparon un lugar destacado. Abdías muestra interés por la cuestión mesiánica y una clara preocupación por las persecuciones de los cristianos hacia los judíos. Esta preocupación puede vincularse a la fiesta de shavu'ot, pues posee carácter político y patriótico, enmarca reacciones históricas importantes contra el ambiente hostil hacia los judíos.

Además de ello, simbólicamente Pentecostés y shavu'ot poseen similitudes relativas al significado de comienzo y a su vez de purificación. El paralelismo entre ambas fiestas es evidente y subraya la posible intencionalidad de Abdías de contraponer su formación como monje cristiano con su conversión al judaísmo en un sustancioso e interesante diálogo entre ambas tradiciones. 